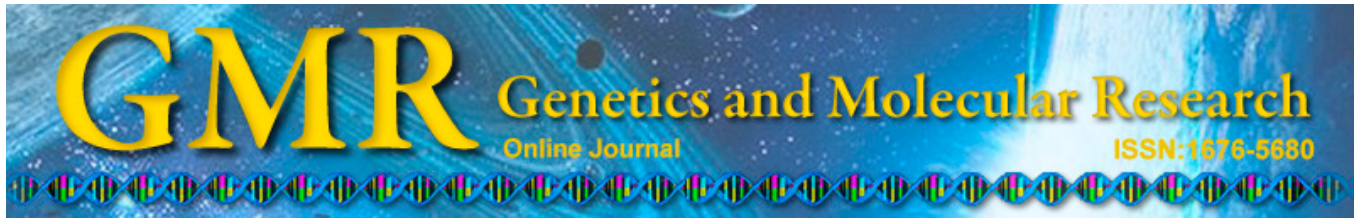

\title{
Association of heat shock protein 70 expression with rat myocardial cell damage during heat stress in vitro and in vivo
}

\author{
H.B. Chen ${ }^{1,2}$, X.C. Zhang ${ }^{1}$, Y.F. Cheng ${ }^{1}$, A. Abdelnasir ${ }^{1}$, S. Tang ${ }^{1}$, \\ N. Kemper ${ }^{3}$, J. Hartung ${ }^{3}$ and E.D. Bao ${ }^{1}$ \\ ${ }^{1}$ College of Veterinary Medicine, Nanjing Agricultural University, \\ Nanjing, China \\ ${ }^{2}$ College of Life Sciences, Longyan University, Longyan, China \\ ${ }^{3}$ Institute for Animal Hygiene, Animal Welfare and Farm Animal Behaviour, \\ University of Veterinary Medicine Hannover, Foundation, Hannover, Germany \\ Corresponding author: E.D. Bao \\ E-mail: b_endong@njau.edu.cn
}

Genet. Mol. Res. 14 (1): 1994-2005 (2015)

Received January 16, 2014

Accepted October 20, 2014

Published March 20, 2015

DOI http://dx.doi.org/10.4238/2015.March.20.9

ABSTRACT. To investigate the mechanism of sudden death as a result
of stress-induced damage to heart tissue and myocardial cells and to
investigate the cardioprotective role of Hsp 70 during heat stress, the
distribution and expression of Hsp 70 was evaluated in the heart cells
of heat-stressed rats in vivo and heat-stressed H9c 2 cells in vitro. After
exposure to heat stress at $42^{\circ} \mathrm{C}$ for different durations, we observed a
significant induction of $\mathrm{CK}, \mathrm{CK}-\mathrm{MB}$, and LDH as well as pathologic
lesions characterized by acute degeneration, suggesting that cell damage
occurs from the onset of heat stress. Immunocytochemistry showed that
Hsp 70 was distributed mainly in the cytoplasm of myocardial cells in
vivo and in vitro. Hsp 70 -positive signals in the cytoplasm were more
prominent in intact areas than in degenerated areas after 60 min of heat
stress. Hsp 70 protein levels in myocardial cells in vitro decreased from
the beginning to the end of heat stress. Hsp 70 protein levels in rat heart 
tissues in vivo decreased gradually with prolonged heat stress, with a slight increase at the beginning of heat stress. These results indicate that Hsp70 plays a role in the response of cardiac cells to heat stress and that decreased Hsp70 levels are associated with damage to rat myocardial cells in vitro and in vivo. Significant differences were found in $h s p 70$ mRNA, which began to increase after 20 min of heat stress in vitro and after $40 \mathrm{~min}$ in vivo. This indicates that hysteresis is involved in mRNA expression after heat stress in vivo.

Key words: Hsp70; Myocardial cells; Heat stress; Rats

\section{INTRODUCTION}

Heat stress is one of the most challenging environmental conditions affecting animals, leading to impaired growth and reducing reproduction. Studies of chronic heat stress have demonstrated altered physiologic, metabolic, biochemical, and cellular responses in animal models and poultry (Hu et al., 2007; Lu et al., 2007). Studies have also confirmed that the sudden death of mammals can occur as a result of stress-induced damage to heart tissue and myocardial cells (Yu et al., 2008; Zhang et al., 2011). The mechanisms leading to cellular damage and the death of animals subjected to such stresses remain poorly understood, although several factors and physiologic reactions have been investigated (Kamarck and Jennings, 1991).

Animals have protective measures against environmental challenges. The heat shock proteins (Hsps) are a set of proteins synthesized in response to physical, chemical, or biological stresses, including heat exposure (McCormick et al., 2003; Ganter et al., 2006; Staib et al., 2007). Hsps are the most broadly distributed class of proteins and are also among the most highly conserved proteins in nature. On the basis of their molecular size, structure, and function, Hsps can be divided into six families of sequence-related proteins: small HSPs, HSP40, HSP60, HSP70, HSP90, and HSP110 (Lindquist and Craig, 1988). Although many Hsps have been shown to be effective in cell survival and adaptation, some are more cardioprotective than others (Liu et al., 2007). Certain Hsps, especially Hsp70, are thought to play particularly important roles in protection against stress-induced cardiac cell damage such as ischemia-reperfusion injury. Hsp70, one of the most abundant and best characterized Hsps, is a molecular chaperone involved in the folding of nascent and misfolded proteins under nonstressful conditions, and it plays a significant role in the protection of cells against various cellular stressors including heat (Čvoro et al., 1998; Evdonin et al., 2006), hypoxia (Dwyer et al., 1989), ultraviolet irradiation (Li et al., 2005), oxidative stress (Drummond and Steinhardt, 1987), and various others (Oyake et al., 2006). The overexpression of Hsp70 can accelerate ulcer healing by promoting cell proliferation, inhibiting cell apoptosis, and accelerating protein synthesis (Pierzchalski et al., 2006). In addition, Hsp70 can minimize infarct size and improve contractile function in humans and mice (Knowlton et al., 1998; Gray et al., 1999). Hsp70 is expressed in the heart and brain and may improve tolerance to environmental changes or pathogenic conditions, increases survival of stressed cells, and plays a critical role in cardiovascular diseases, organism decay, and cellular aging (Njemini et al., 2007).

Lethal heart pathologies such as cardiac failure and stroke result from damage caused by various factors, including heat, toxins, impairment of transport and physiologic functions, and ischemia (Gisolfi et al., 1991). Severe stress can lead to sudden death in humans or animals 
due to the cardiac dysfunction induced by heart damage (Hobbesland et al., 1997). Studies on thermal stress have shown that high temperatures can result in lethal heart injury or damage (Rai and Ambwany, 1980; Gathiram et al., 1987, 1988), and various types of stressor, such as transport in pigs and heat in poultry, can lead to sudden death (Vecerek et al., 2006; Yu et al., 2008). Death is usually due to damage to the heart, although various changes occur in other organs.

Little is known about the expression of Hsp70 in response to heat stress or the effect of its distribution and levels in protection against hyperthermia-induced cellular damage. The mechanisms by which heat stress causes cell damage are difficult to investigate systematically in vivo due to the numerous confounding environmental variables. The aims of this study were to investigate the expression of the Hsp70 protein and its mRNA and the potential role of Hsp70 in protection against heat-induced cellular damage in vivo and in vitro.

\section{MATERIAL AND METHODS}

\section{Models of heat stress using cell culture in vitro and experimental rats in vivo}

H9c2 cells were purchased from the Type Culture Collection of the Chinese Academy of Sciences (Shanghai, China). The cells were cultured in Dulbecco's modified Eagle's medium supplemented with $10 \%$ fetal bovine serum, $100 \mathrm{U} / \mathrm{mL}$ penicillin, and $100 \mu \mathrm{g} / \mathrm{mL}$ streptomycin in a humidified atmosphere of $5 \% \mathrm{CO}_{2}$ at $37^{\circ} \mathrm{C}$. At cellular viability greater than $95 \%$, the cells were divided into six groups and exposed to heat stress in a water bath at $42^{\circ} \mathrm{C}$ for 0 (control), 20, 40, 60, 80, or 100 min, respectively.

Sixty Sprague Dawley rats, $220 \pm 20$ g, were purchased from Qinglongshan Farms (Nanjing, China) and housed in cages with free access to food and water. After 3 days of adaptation feeding at room temperature, all animals were suddenly exposed to $42^{\circ} \mathrm{C}$ in climatecontrolled chambers (RX8-500D, New Jiangnan Instrument Co., Ltd., Ningbo, China) for 0 (control), 20, 40, 60, 80, or 100 min, with 10 rats in each group. All experimental rats were humanely killed by decapitation at the end of the heat stress period. All experiments were performed in accordance with the guidelines of the Animal Ethics Committee of Jiangsu Province, China, and were approved by the institutional animal care and use committee of Nanjing Agricultural University, China.

\section{Determination of enzyme activities in vitro and in vivo}

The activities of creatine kinase (CK, A032), the MB isoenzyme of CK (CK-MB, H197), and lactate dehydrogenase (LDH, A-020-1) in all samples were measured according to the instructions provided with commercial kits (Nanjing Jiancheng Biochemical Reagent Co. Ltd., Nanjing, China). Each sample was analyzed five consecutive times.

\section{Immunofluorescence staining of heat-stressed myocardial cells in vitro and in vivo}

After heat stress, H9c2 cells on glass-bottomed dishes were fixed with $4 \%$ paraformaldehyde. Cells were incubated with anti-Hsp70 (1:50) (ADI-SPA-820-F, Enzo Life Sciences, USA) mouse monoclonal antibody and subsequently incubated with fluorescein isothiocyanate-conjugated antibody. Fluorescence images were taken using light microscopy. 
Serial sections of heart tissues were immunostained by the standard avidin-biotin complex immunoperoxidase method as previously described (Yu et al., 2008). The sections were counterstained with hematoxylin, and fluorescence images were taken using light microscopy. Corresponding negative control sections were prepared by omitting antibody.

\section{Determination of Hsp70 in heat-stressed myocardial cells in vitro and in vivo by western blotting}

Heat-stressed H9c2 cell protein was extracted using M-PER Mammalian Protein Extraction Reagent (78501; Thermo Scientific, Waltham, MA, USA) according to the manufacturer protocol. Heart tissue samples were homogenized in $1 \mathrm{~mL}$ protein extraction reagent on ice using an Ultra-Turrax homogenizer after being completely washed in ice-cold physiological saline; the homogenates were then centrifuged at $12,000 \mathrm{~g}$ for $20 \mathrm{~min}$ at $4^{\circ} \mathrm{C}$ to remove cellular debris. The supernatant was collected and stored at $-20^{\circ} \mathrm{C}$ for protein quantification. Protein concentrations were measured using a Micro BCA assay kit (23235; Thermo Scientific). The bands on the developed film were quantified using the Quantity One software version 4.6.2 (Bio-Rad, Hercules, CA, USA). All blots were probed with anti-GAPDH (KC-5G4; KangChen Bio-tech Inc., Shanghai, China) antibody as an internal control.

\section{Determination of $h s p 70 \mathrm{mRNA}$ in heat-stressed myocardial cells in vitro and in vivo by quantitative real-time polymerase chain reaction (qPCR)}

Total RNA was isolated using TRIzol reagent (15596-026; Invitrogen, Thermo Fisher Scientific Inc., USA) according to manufacturer instructions. The concentration of RNA was determined with a spectrophotometer (Infinite M200PRO, Tecan, Austria). Primer sets were specifically designed to anneal to each target mRNA. The sequences of $h s p 70 \mathrm{mRNA}$ and $\beta$-actin mRNA were obtained from the National Center for Biotechnology Information's GenBank (Table 1). The amplification efficiencies of the target and reference were approximately equal. Therefore, the $h s p 70 \mathrm{mRNA}$ levels were normalized using the following formula:

Relative quantity of $h s p 70 \mathrm{mRNA}=2^{-\Delta \Delta C t}$

$$
-\Delta \Delta C t=-\left\{\left[\left(C t_{h s p 70 m R N A}-C t_{\beta-a c t i n R N A}\right) \text { heat stress group }\right]-\left[\left(C t_{h s p 70 m R N A}-C t_{\beta-\text { actin mRNA }}\right) \text { control group }\right]\right\}
$$

Table 1. Primers for quantitative real time polymerase chain reaction.

\begin{tabular}{|c|c|c|c|}
\hline Gene & Amplicon size (bp) & Sense primer $\left(5^{\prime}-3^{\prime}\right)$ & Antisense primer (5'-3') \\
\hline hsp 70 & 95 & GCTGACCAAGATGAAGGAGAT & GCTGCGAGTCGTTGAAGTAG \\
\hline$\beta$-actin & 184 & TGCGCAAGTTAGGTTTTGTCA & GCAGGAGTACGATGAGTCCG \\
\hline
\end{tabular}

\section{Statistical analysis}

Statistical analysis of the differences between the experimental groups and the control group were performed with one-way analysis of variance followed by the least significant difference multiple comparison test provided by SPSS version 20.0 for Windows (IBM, Armonk, NY, USA). Results are reported as means \pm SE of at least three independent experiments. $\mathrm{P}<$ 0.05 was considered to be statistically significant. 


\section{RESULTS}

\section{Damage-related enzyme activities in vitro and in vivo}

Significant changes in CK, CK-MB, and LDH levels were observed in the heatstressed rat myocardial cells compared with the control group (Table 2). From the beginning of heat stress, almost all enzyme activities tested were increased significantly in vitro and in vivo, especially in the culture supernatant from myocardial cells in vitro. CK-MB and LDH levels were significantly increased after $20 \mathrm{~min}$ of heat stress $(\mathrm{P}<0.05)$, and $\mathrm{CK}$ was significantly increased after $40 \mathrm{~min}(\mathrm{P}<0.05)$ in vitro. However, these enzymes showed no significant changes in vivo until at least $40 \mathrm{~min}$ of heat stress. CK-MB and LDH were significantly increased after $40 \mathrm{~min}(\mathrm{P}<0.05)$, and $\mathrm{CK}$ was significantly increased at $100 \mathrm{~min}(\mathrm{P}<0.05)$.

\begin{tabular}{|c|c|c|c|c|c|c|c|}
\hline \multicolumn{2}{|c|}{ Heat stress time (min) } & \multicolumn{6}{|c|}{ Heat stress group } \\
\hline & & 0 & 20 & 40 & 60 & 80 & 100 \\
\hline \multirow[t]{3}{*}{ In vitro } & CK-MB (U/L) & $4.53 \pm 0.59$ & $5.27 \pm 0.82 *$ & $6.00 \pm 1.10^{* *}$ & $5.83 \pm 0.98^{*}$ & $6.17 \pm 0.98 * *$ & $7.17 \pm 0.75^{* *}$ \\
\hline & $\mathrm{CK}(\mathrm{U} / \mathrm{L})$ & $8.17 \pm 1.33$ & $9.33 \pm 1.74^{*}$ & $10.17 \pm 1.83 *$ & $10.57 \pm 0.75 *$ & $12.83 \pm 1.67 * *$ & $11.33 \pm 1.63 * *$ \\
\hline & LDH (U/L) & $53.83 \pm 2.79$ & $58.17 \pm 5.71^{*}$ & $61.67 \pm 3.20 * *$ & $63.00 \pm 6.45^{* *}$ & $64.83 \pm 5.04 * *$ & $67.67 \pm 5.37 * *$ \\
\hline \multirow[t]{3}{*}{ In vivo } & CK-MB (U/L) & $2079 \pm 782$ & $2426 \pm 758$ & $2817 \pm 609^{*}$ & $3297 \pm 634^{* *}$ & $2991 \pm 905^{*}$ & $3448 \pm 1324 * *$ \\
\hline & $\mathrm{CK}(\mathrm{U} / \mathrm{L})$ & $4334 \pm 778$ & $6186 \pm 2771$ & $6272 \pm 2461$ & $5973 \pm 2677$ & $6113 \pm 2725$ & $7657 \pm 2771^{*}$ \\
\hline & LDH (U/L) & $2455 \pm 961$ & $2871 \pm 889$ & $3027 \pm 612 *$ & $3858 \pm 761 * *$ & $3263 \pm 839^{*}$ & $3822 \pm 1023^{* *}$ \\
\hline
\end{tabular}

$* \mathrm{P}<0.05$ and $* * \mathrm{P}<0.01$ compared with controls. Values are reported as means $\pm \mathrm{SE}$.

\section{Pathologic lesion and Hsp70 distribution in heat-stressed myocardial cells in vitro and in vivo}

In the control group, no obvious lesions were found in the cells (Figure 1A). Cytopathologic acute degeneration characterized by numerous fine granular particles in the cytoplasm and enlarged cellular size was observed in myocardial cells after heat stress in vitro (Figure 1B). Positive Hsp70 signals were observed mainly in the cytoplasm and less in the nucleus of the myocardial cells in the non-heat-stressed group (Figure 1C). After 60 min of heat stress, Hsp70 signals were observed in both the nucleus and the cytoplasm, although the cytoplasmic signals were weak (Figure 1D).

There were no obvious lesions in the control group in vivo (Figure 2A). After exposure to high temperature for $60 \mathrm{~min}$, hyperemia and edema characterized by wider spaces among muscle fibers were observed. The myocardial cells were enlarged (Figure 2B). Hsp70 signals were observed mainly in the cytoplasm and occasionally in the nucleus of myocardial cells in vivo in both the control (Figure 2C) and the heat-stressed rats. Although there was no obvious difference in Hsp70 distribution between the heat-stressed rats and the controls, positive Hsp70 signals in the cytoplasm were more prominent in intact areas than in degenerated areas after $60 \mathrm{~min}$ of heat stress (Figure 2D).

In rats that died from heat stress, bleeding among myocardial cells and partial collapse of myocardial fibers were observed. Hsp70-positive signals were weakly and unevenly distributed in the cytoplasm of myocardial cells from the heat-stressed rats in vivo (Figure 3A, B). 


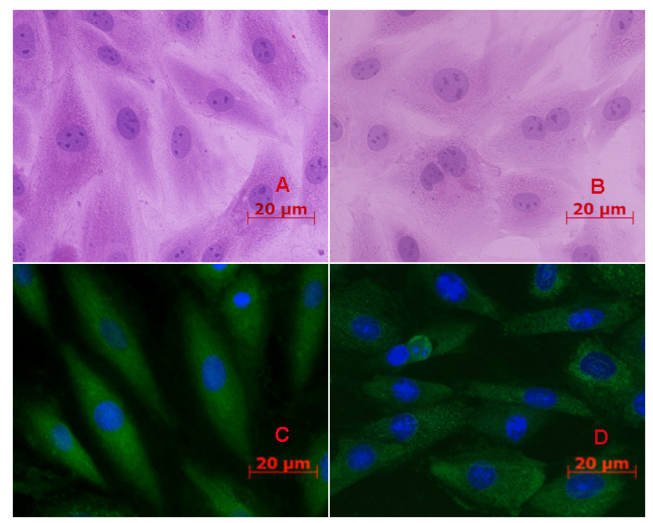

Figure 1. Cytopathologic changes and Hsp70 distribution in heat-stressed H9c2 cells in vitro. Scale bar = $20 \mu \mathrm{m}$. A. Hematoxylin and eosin (HE) staining. Myocardial cells incubated at $37^{\circ} \mathrm{C}$ (control group). B. HE staining. After $60 \mathrm{~min}$ of heat stress, obvious cloudy cytoplasm in the swelling myocardial cells was observed. C. Immunofluorescence staining. Hsp70 signals mainly distributed in the cytoplasm of myocardial cells in vitro. D. Immunofluorescence staining. Weak positive signals for Hsp70 were observed in the cytoplasm of the enlarged myocardial cells after 60 min of heat stress compared with the control group.

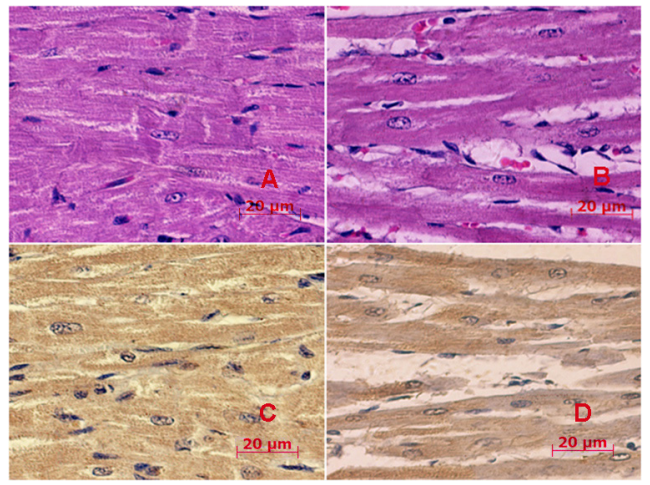

Figure 2. Histopathologic changes and Hsp70 distribution in heatstressed rat myocardial cells in vivo. A. Hematoxylin and eosin (HE) staining. Myocardial cells from control group raised at $37^{\circ} \mathrm{C}$, showing no obvious histopathologic changes. B. HE staining. After $60 \mathrm{~min}$ of heat stress, hyperemia, edema, and granular degeneration were observed in heart tissue. C. Immunofluorescence staining. Positive Hsp70 signals were mainly detected in the cytoplasm of myocardial cells from control ratsin vivo. D. Immunofluorescence staining. After 60 min of heat stress, positive Hsp70 signals were unevenly distributed in the cytoplasm of myocardial cells from heat stressed rats in vivo.

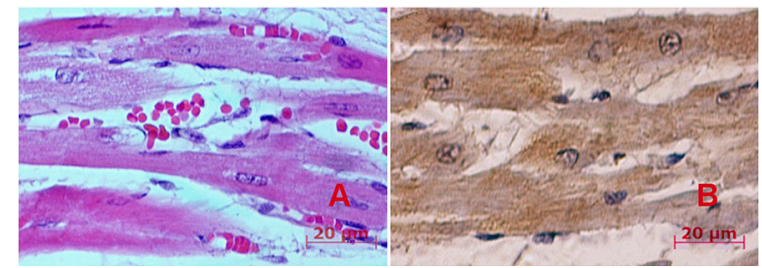

Figure 3. Histologic images of myocardial cells from rats that died from heat stress. A. Hematoxylin and eosin (HE) staining. Myocardial fibers were unevenly stained and hemorrhage among myocardial fibers was observed. B. Weak Hsp70 positive signals were unevenly distributed in the cytoplasm of myocardial cells. 


\section{Changes of Hsp70 and $h s p 70$ mRNA in heat-stressed myocardial cells in vitro and} in vivo

Changes of Hsp70 and hsp 70 mRNA in myocardial cells in vitro and in vivo after heat stress are shown in Figures 4 and 5, respectively.

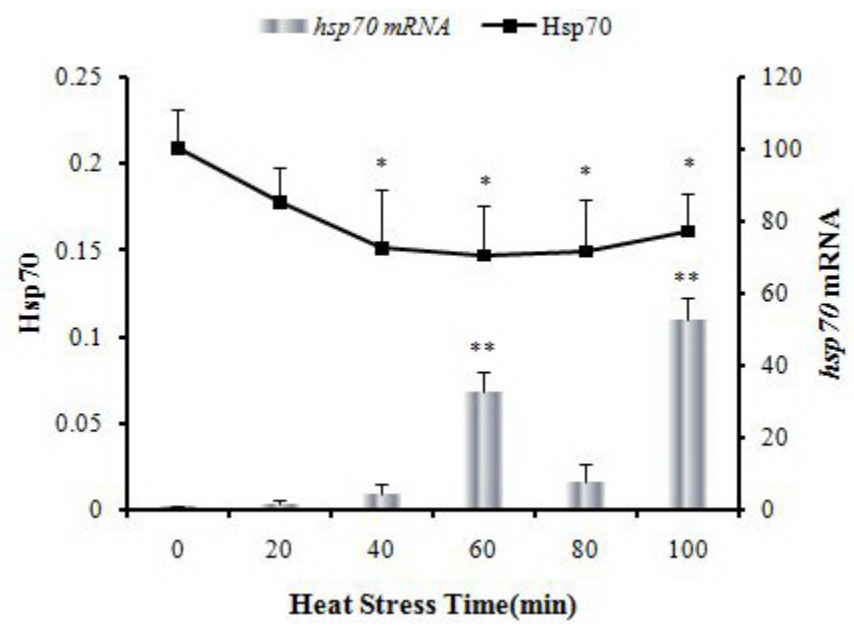

Figure 4. Hsp70 and $h s p 70$ mRNA changes in heat-stressed H9c2 cells in vitro. Values are reported as means $\pm \mathrm{SE}$. $* \mathrm{P}<0.05, * * \mathrm{P}<0.01, \mathrm{~N}=6$.

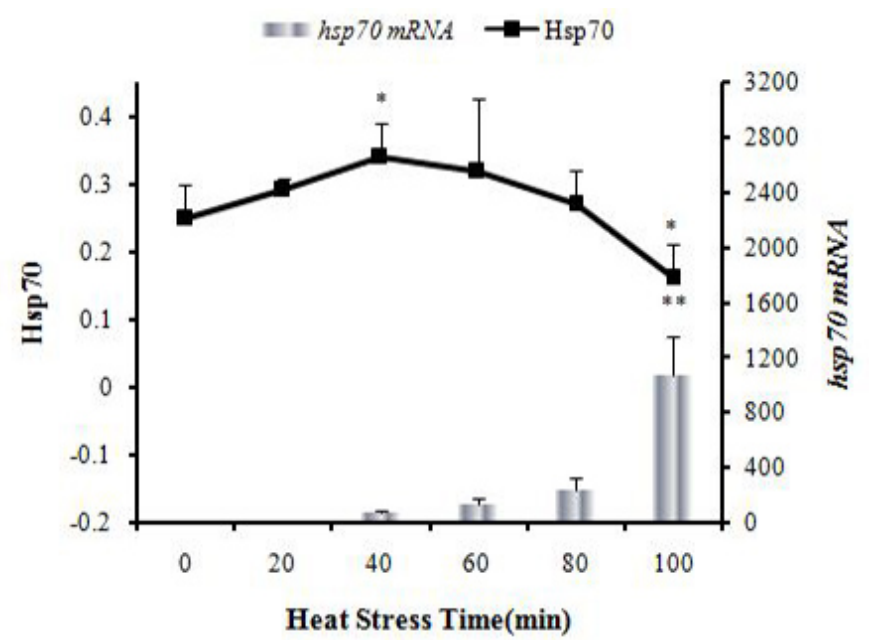

Figure 5. Hsp70 and hsp $70 \mathrm{mRNA}$ changes in myocardial cells from heat stressed rats in vivo. Values are reported as means $\pm \mathrm{SE}$. $* \mathrm{P}<0.05,{ }^{*} * \mathrm{P}<0.01, \mathrm{~N}=10$.

The expression of Hsp70 in vitro was decreased compared with controls from the beginning of heat stress (20 min), with obvious reductions at $40 \mathrm{~min}$. The expression of Hsp70 protein remained low until the end of the experimental period, although with slight increases 
at 80 and $100 \mathrm{~min}$. However, the transcription of $h s p 70$ mRNA was increased from the beginning of heat stress $(\mathrm{P}>0.05)$, with significant induction at $60(\mathrm{P}<0.01)$ and $100 \min (\mathrm{P}<0.01)$ compared with the control group.

Hsp70 in the heart tissues of rats in vivo was increased from the beginning of heat stress, was the greatest at $40 \mathrm{~min}(\mathrm{P}<0.05)$, and then decreased gradually with prolonged heat stress; at $100 \mathrm{~min}, \mathrm{Hsp} 70$ expression was decreased significantly $(\mathrm{P}<0.05)$. However, the transcription of $h s p 70 \mathrm{mRNA}$, which increased gradually from the beginning of heat stress, was greatest at $100 \mathrm{~min}(\mathrm{P}<0.01)$.

Interestingly, the levels of Hsp70 in the heart tissues of rats that died of heat stress were significantly reduced $(\mathrm{P}<0.01)$ compared with those in the control rats (Figure 6), although the transcription of $h s p 70$ mRNA was significantly increased.

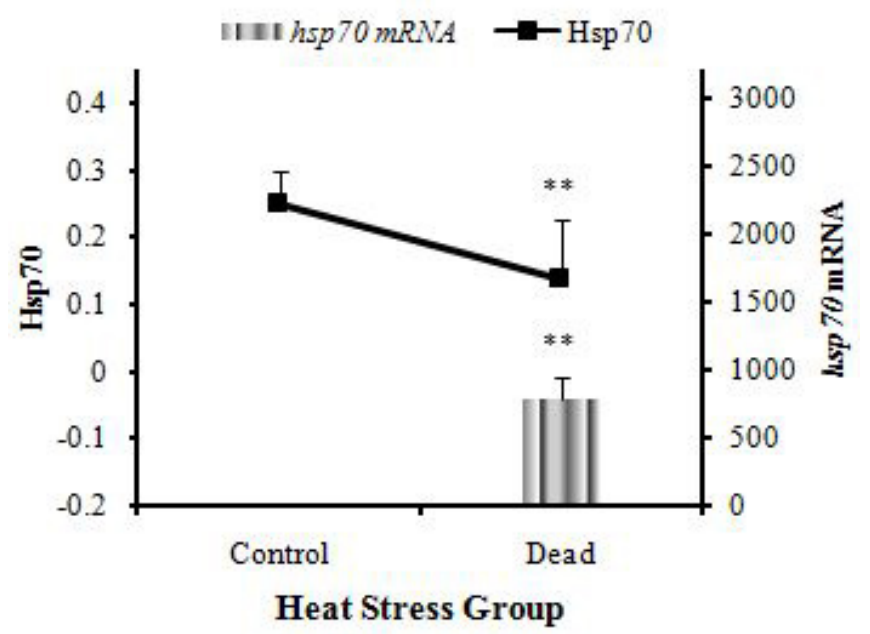

Figure 6. Hsp70 and $h s p 70$ mRNA changes in myocardial cells from rats that died from heat stress. Values are reported as means $\pm \mathrm{SE}$. $* \mathrm{P}<0.05, * * \mathrm{P}<0.01$.

\section{DISCUSSION}

In this study, the induction of myocardial cell damage by heat stress was confirmed by determining levels of the enzymes CK, CK-MB, and LDH, which are used as indicators of cardiac function when investigating damage to the heart not only in humans but also in livestock (Georgopoulos and Welch, 1993; Mitchell and Sandercock, 1995; Lin et al., 2001; Buyukokuroglu et al., 2004; Saravanan et al., 2011). The levels of CK, CK-MB, and LDH activity were higher in heat-stressed myocardial cells than in the control group after various time intervals both in vitro and in vivo, although myocardial cells had sustained considerable damage after only $20 \mathrm{~min}$ in vitro, whereas in vivo heart tissues were damaged later, particularly at the end of the heat stress period. This suggests that hysteresis is involved in myocardial cell damage by heat stress in vivo compared with in vitro.

Although positive Hsp70 signals were detected in both the nucleus and the cytoplasm of myocardial cells in vitro and in vivo, stronger signals were mainly in the cytoplasm. This 
is in agreement with many previous observations (Bao et al., 2008; Yu et al., 2008). Our immunofluorescence results show that Hsp70-positive signals decreased slightly after heat stress without any change in distribution. The localization of Hsps may be related to the protective function of molecular chaperones (Georgopoulos and Welch, 1993; Craig et al., 1994; Hendrick and Hartl, 1995). With regard to the role of Hsps in cardiac damage, our immunofluorescence results indicate that the distribution of Hsp70 in myocardial cells varied with the duration of exposure to heat stress and differed from that in the control cells even after exposure to heat for only a short period of time. These findings are in agreement with those of another study, in which these proteins were expressed dynamically in rat primary myocardial cells subjected to stress (Geum et al., 2002). Similar to the in vitro experiments, our immunofluorescence results in vivo showed that the expression of Hsp70 in myocardial cells after 60 min of heat stress was weaker than that in the control group. Immunohistochemistry in vitro showed weaker Hsp70-positive signals after $60 \mathrm{~min}$ of heat stress, which was consistent with our western blotting results. Immunohistochemistry in vivo also revealed weaker Hsp70-positive signals after $60 \mathrm{~min}$ of heat stress; however, western blotting showed that Hsp70 expression at that time was greater than that in the control group. Focusing on the distribution of Hsp70 and its relationship with the pathologic changes, our cytopathologic and histopathologic results demonstrate that acute myocardial cell degeneration or heart tissue damage and muscle fiber disruption occurred after $60 \mathrm{~min}$ of heat stress both in vitro and in vivo. Meanwhile, the distribution densities of Hsp70 were decreased. Hsp70-positive signals in the cytoplasm of heart cells were more prominent in intact areas than in degenerated areas after 60 min of heat stress. Our findings indicate that decreased Hsp70 levels are associated with severe damage to rat myocardial cells in vitro and in vivo.

Our western blotting results showed that Hsp70 expression varied in myocardial cells exposed to heat stress in vitro and in vivo. Levels started to decline after $20 \mathrm{~min}$ and reached their lowest point after $60 \mathrm{~min}$ in vitro. In vivo, however, Hsp70 expression was increased from the beginning of heat stress $(20 \mathrm{~min})$, reached its highest levels at $40 \mathrm{~min}$, then decreased significantly after $80 \mathrm{~min}$ and especially after $100 \mathrm{~min}$. Interestingly, Hsp70 levels in the heart tissues of rats that died from heat stress were also decreased significantly compared with the levels of control rats. Our findings are partly consistent with those of previous reports (Bao et al., 2008; Yu et al., 2008) and indicate that hysteresis is involved in Hsp70 expression after heat stress in vivo but not in vitro. The reason for this difference may be due to the presence of more complex regulatory mechanisms against heat stress, such as neuroendocrine regulation, in vivo (Haley et al., 2006; Weinberg et al., 2008; Holsen et al., 2013).

The changes in $h s p 70$ mRNA transcription that were observed in myocardial cells in vitro and in vivo were relatively consistent. Both were raised significantly from the beginning until the end of heat stress and increased gradually with the duration of heat stress. Even in the myocardial cells of rats that died from heat stress, $h s p 70$ mRNA transcription was increased and remained higher than in the control group. This is in agreement with many previous observations (Banerji et al., 1986). However, the observed changes in Hsp70 protein did not correspond to changes in $h s p 70$ mRNA transcription in vitro or in vivo in the present study. Hsp70 protein was significantly decreased in vitro or was increased initially and then decreased in vitro. This is inconsistent with the classic patterns of transcription and translation and implies that the expression of Hsp70, which is required for myocardial cell homeostasis in response to stress, was delayed or overtaxed due to rapid consumption at the onset of heat stress. 
Members of the Hsp70 family are known to inhibit cell death by multiple mechanisms (Garrido et al., 2006). Heat stress can have serious effects on the body, including acidbase balance disorders, intracellular protein misfolding, and even death. An important role of Hsp70 is cytoskeletal stabilization and the management of protein folding and repair. Under stress conditions, Hsp70 combines with misfolded or aggregated proteins to reduce the risk of formation of insoluble aggregates, and helps in correct protein folding, maintaining certain peptide chains in their extended state. Exposure to potentially fatal heat stress causes rapid intracellular protein misfolding in myocardial cells in vitro. The rapid combination of Hsp70 with misfolded proteins decreases Hsp70 levels. Animals subjected to heat stress attempt to eliminate damage by maintaining homeostasis, but homeostasis is destroyed when the stress persists and Hsp70 levels gradually become insufficient. Large quantities of insoluble aggregates affect cardiac function and can lead to death. In the present study, Hsp70 levels in the myocardial cells of rats that died from heat stress were much lower than those in the other heat-stressed rats in vivo. This may be partly due to the presence of insufficient Hsp70 to protect the cells from heat stress damage. However, the mechanisms of the interaction between Hsp70 and tissue damage in heat-stressed cells in vivo and in vitro require confirmation in further studies.

\section{ACKNOWLEDGMENTS}

Research supported by grants from the National Key Basic Research Program of China (973 Program) (\#2014CB138502), the National Natural Science Foundation of China (\#31372403), the National Department Public Benefit Research Foundation (Agriculture) (\#201003060-11), the Priority Academic Program Development of Jiangsu Higher Education Institutions (PAPD), Graduate research and innovation projects in Jiangsu Province, and the Sino-German Agricultural Cooperation Project of the Federal Ministry of Food, the Agriculture and Consumer Production, Berlin, Germany.

\section{REFERENCES}

Banerji SS, Berg L and Morimoto RI (1986). Transcription and post-transcriptional regulation of avian HSP70 gene expression. J. Biol. Chem. 261: 15740-15745.

Buyukokuroglu ME, Taysi S, Buyukavci M and Bakan E (2004). Prevention of acute adriamycin cardiotoxicity by dantrolene in rats. Hum. Exp. Toxicol. 23: 251-256

Bao E, Sultan K, Nowak B and Hartung J (2008). Expression and distribution of heat shock proteins in the heart of transported pigs. Cell Stress Chaperones 13: 459-466.

Craig EA, Weissman JS and Horwich AL (1994). Heat shock proteins and molecular chaperones: mediators of protein conformation and turnover in the cell. Cell 78: 365-372.

Čvoro A, Dundjerski J, Trajković D and Matić G (1998). Heat stress affects the glucocorticoid receptor interaction with heat shock protein Hsp70 in the rat liver. Biochem. Mol. Biol. Int. 46: 63-70.

Drummond IA and Steinhardt RA (1987). The role of oxidative stress in the induction of Drosophila heat-shock proteins. Exp. Cell Res. 173: 439-449.

Dwyer BE, Nishimura RN and Brown IR (1989). Synthesis of the major inducible heat shock protein in rat hippocampus after neonatal hypoxia-ischemia. Exp. Neurol. 104: 28-31.

Evdonin AL, Guzhova IV, Margulis BA and Medvedeva ND (2006). Extracellular heat shock protein 70 mediates heat stress-induced epidermal growth factor receptor transactivation in A431 carcinoma cells. FEBS Lett. 580: 6674-6678.

Ganter MT, Ware LB, Howard M, Roux J, et al. (2006). Extracellular heat shock protein 72 is a marker of the stress protein response in acute lung injury. Am. J. Physiol. Lung Cell. Mol. Physiol. 291: L354-L361.

Garrido C, Brunet M, Didelot C, Zermati Y, et al. (2006). Heat shock proteins 27 and 70: anti-apoptotic proteins with 
tumorigenic properties. Cell Cycle 5: 2592-2601.

Gathiram P, Gaffin SL, Brock-Utne JG and Wells MT (1987). Time course of endotoxemia and cardiovascular changes in heat-stressed primates. Aviat. Space Environ. Med. 58: 1071-1074.

Gathiram P, Wells MT, Raidoo D, Brock-Utne JG, et al. (1988). Portal and systemic plasma lipopolysaccharide concentrations in heat-stressed primates. Circ. Shock 25: 223-230.

Georgopoulos C and Welch WJ (1993). Role of the major heat shock proteins as molecular chaperones. Annu. Rev. Cell Biol. 9: 601-634.

Geum D, Son GH and Kim K (2002). Phosphorylation-dependent cellular localization and thermoprotective role of heat shock protein 25 in hippocampal progenitor cells. J. Biol. Chem. 277: 19913-19921.

Gisolfi CV, Matthes RD, Kregel KC and Oppliger R (1991). Splanchnic sympathetic nerve activity and circulating catecholamines in the hyperthermic rat. J. Appl. Physiol. 70: 1821-1826.

Gray CC, Amrani M and Yacoub MH (1999). Heat stress proteins and myocardial protection: experimental model or potential clinical tool? Int. J. Biochem. Cell Biol. 31: 559-573.

Haley DW, Handmaker NS and Lowe J (2006). Infant stress reactivity and prenatal alcohol exposure. Alcohol Clin. Exp. Res. 30: 2055-2064.

Hendrick JP and Hartl FU (1995). The role of molecular chaperones in protein folding. FASEB J. 9: 1559-1569.

Hobbesland A, Kjuus H and Thelle DS (1997). Mortality from cardiovascular diseases and sudden death in ferroalloy plants. Scand. J. Work Environ. Health 23: 334-341.

Holsen L, Lancaster K, Klibanski A, Whitfield-Gabrieli S, et al. (2013). HPA-axis hormone modulation of stress response circuitry activity in women with remitted major depression. Neuroscience 250: 733-742.

$\mathrm{Hu}$ Y, Jin H, Du X, Xiao C, et al. (2007). Effects of chronic heat stress on immune responses of the foot-and-mouth disease DNA vaccination. DNA Cell Biol. 26: 619-626.

Kamarck T and Jennings JR (1991). Biobehavioral factors in sudden cardiac death. Psychol. Bull. 109: 42-75.

Knowlton AA, Kapadia S, Torre-Amione G, Durand JB, et al. (1998). Differential expression of heat shock proteins in normal and failing human hearts. J. Mol. Cell. Cardiol. 30: 811-818.

Li HM, Niki T, Taira T, Iguchi-Ariga SM, et al. (2005). Association of DJ-1 with chaperones and enhanced association and colocalization with mitochondrial Hsp70 by oxidative stress. Free Radic. Res. 39: 1091-1099.

Lin YH, Chiu JH, Tung HH, Tsou MT, et al. (2001). Preconditioning somatothermal stimulation on right seventh intercostal nerve territory increases hepatic heat shock protein 70 and protects the liver from ischemia-reperfusion injury in rats. J. Surg. Res. 99: 328-334.

Lindquist S and Craig EA (1988). The heat-shock proteins. Annu. Rev. Genet. 22: 631-677.

Liu L, Zhang X, Qian B, Min X, et al. (2007). Over-expression of heat shock protein 27 attenuates doxorubicin-induced cardiac dysfunction in mice. Eur. J. Heart Fail. 9: 762-769.

Lu Q, Wen J and Zhang H (2007). Effect of chronic heat exposure on fat deposition and meat quality in two genetic types of chicken. Poult. Sci. 86: 1059-1064.

McCormick P, Chen G, Tlerney S, Kelly C, et al. (2003). Clinically relevant thermal preconditioning attenuates ischemiareperfusion injury. J. Surg. Res. 109: 24-30.

Mitchell MA and Sandercock DA (1995). Creatine kinase isoenzyme profiles in the plasma of the domestic fowl (Gallus domesticus): effects of acute heat stress. Res. Vet. Sci. 59: 30-34.

Njemini R, Bautmans I, Lambert M, Demanet C, et al. (2007). Heat shock proteins and chemokine/cytokine secretion profile in ageing and inflammation. Mech. Ageing Dev. 128: 450-454.

Oyake J, Otaka M, Matsuhashi T, Jin M, et al. (2006). Over-expression of 70-kDa heat shock protein confers protection against monochloramine-induced gastric mucosal cell injury. Life Sci. 79: 300-305.

Pierzchalski P, Krawiec A, Ptak-Belowska A, Barańska A, et al. (2006). The mechanism of heat shock protein 70 gene expression abolition in gastric epithelium caused by Helicobacter pylori infection. Helicobacter 11: 96-104.

Rai U and Ambwany P (1980). Cardiovascular changes during varied thermal stress. Indian J. Physiol. Pharmacol. 24: $119-125$.

Saravanan G, Ponmurugan P, Sathiyavathi M, Vadivukkarasi S, et al. (2011). Cardioprotective activity of Amaranthus viridis Linn: effect on serum marker enzymes, cardiac troponin and antioxidant system in experimental myocardial infarcted rats. Int. J. Cardiol. 165: 494-498.

Staib JL, Quindry JC, French JP, Criswell DS, et al. (2007). Increased temperature, not cardiac load, activates heat shock transcription factor 1 and heat shock protein 72 expression in the heart. Am. J. Physiol. Regul. Integr. Comp. Physiol. 292: R432-R439.

Vecerek V, Grbalova S, Voslarova E, Janackova B, et al. (2006). Effects of travel distance and the season of the year on death rates of broilers transported to poultry processing plants. Poult. Sci. 85: 1881-1884.

Weinberg J, Sliwowska J, Lan N and Hellemans K (2008). Prenatal alcohol exposure: foetal programming, the 
hypothalamic-pituitary-adrenal axis and sex differences in outcome. J. Neuroendocrinol. 20: 470-488.

Yu J, Bao E, Yan J and Lei L (2008). Expression and localization of Hsps in the heart and blood vessel of heat-stressed broilers. Cell Stress Chaperones 13: 327-335.

Zhang M, Xin L, Bao E, Hartung J, et al. (2011). Variation in the expression of Hsp27, alphaB-crystallin mRNA and protein in heart and liver of pigs exposed to different transport times. Res. Vet. Sci. 90: 432-438. 